Proceedings of the CSMAG'07 Conference, Košice, July 9-12, 2007

\title{
Thermomagnetic Behaviour and Microstructure of a Rapidly Quenched $\mathrm{Nd}_{4.5} \mathrm{Fe}_{77} \mathrm{~B}_{18.5}$ Alloy
}

\author{
N. Talijan, V. Ćosović, A. Grujić, J. Stajić-Trošić \\ Institute of Chemistry, Technology and Metallurgy, University of Belgrade \\ Njegoševa 12, 11000 Belgrade, Serbia
}

AND T. ŽÁK

Institute of Physics of Materials, Academy of Sciences of the Czech Rep., v.v.i.

Žižkova 22, 61662 Brno, Czech Republic

\begin{abstract}
Changes in the phase composition and crystallite size, as well as changes in the magnetic behaviour of $\mathrm{Nd}_{4.5} \mathrm{Fe}_{77} \mathrm{~B}_{18.5}$ alloy, caused by thermomagnetic measurements, was observed in regard of the optimal magnetic state of this alloy. In the optimized magnetic state, the formed nanocomposite consisted of $\mathrm{Fe}_{3} \mathrm{~B} / \mathrm{Nd}_{2} \mathrm{Fe}_{14} \mathrm{~B}$ and partly of $\alpha$-Fe with a mean crystallite size $<30 \mathrm{~nm}$, as determined by $\mathrm{X}$-ray diffraction and transmission electron microscopy. An increased amount of $\alpha$-Fe, the presence of $\mathrm{Nd}_{2} \mathrm{O}_{3}$ and different $\mathrm{Fe}-\mathrm{B}$ phases, as well as an increase in the mean crystallite size were observed after thermomagnetic measurements had caused a quality loss of the hard magnetic properties.
\end{abstract}

PACS numbers: 81.40.Rs

\section{Introduction}

The microstructure of $\mathrm{Nd}-\mathrm{Fe}-\mathrm{B}$ alloys with a low content of $\mathrm{Nd}$ consists of a hard magnetic phase: $\mathrm{Nd}_{2} \mathrm{Fe}_{14} \mathrm{~B}$, soft magnetic phases: $\alpha$-Fe and/or $\mathrm{Fe}_{3} \mathrm{~B}$ phase and a variety of $\mathrm{Fe}-\mathrm{B}$-type phases. The main condition for obtaining a nano-composite structure is the homogeneous dispersion of a hard phase in a soft phase with a mean grain size in the nano scale $(<40 \mathrm{~nm})$, because intergranullar coupling between the phases only becomes more pronounced in the nano scale [1]. The formed nanocomposites $\mathrm{Fe}_{3} \mathrm{~B} / \mathrm{Nd}_{2} \mathrm{Fe}_{14} \mathrm{~B}$ and/or $\alpha$ - $\mathrm{Fe} / \mathrm{Nd}_{2} \mathrm{Fe}_{14} \mathrm{~B}$ are directly responsible for an increase in remanence and magnetic energy. In this work, some of the results of size-strain analysis and quantitative phase analysis obtained by X-ray diffraction (XRD) of $\mathrm{Nd}_{4.5} \mathrm{Fe}_{77} \mathrm{~B}_{18.5}$ alloy in the optimized magnetic state and after thermomagnetic measurements (TM) and the corresponding magnetic behaviour are reported and discussed.

\section{Experimental}

The $\mathrm{Nd}_{4.5} \mathrm{Fe}_{77} \mathrm{~B}_{18.5}$ alloy was produced by centrifugal atomization and its magnetic characteristics in the optimized magnetic state were $H_{\mathrm{c}}=2.8 \mathrm{kOe}$, 
$B_{\mathrm{r}}=10.9 \mathrm{kGs}$ and $(B H)_{\max }=10.7$ MGOe. TM in the temperature interval $20-800^{\circ} \mathrm{C}$ were performed using a vibrating sample magnetometer in a field of intensity 50 Oe under vacuum. The phase composition and crystallite size in the optimized magnetic state and after TM were determined by XRD analysis using an X'Pert PRO MPD diffractometer from PANanalytical with Co $K_{\alpha}$ radiation. The size-strain analysis and quantitative phase analysis of the obtained XRD data were realised using FullProf software [2]. The X-ray line broadenings were analysed through refinement of the $\mathrm{TCH}-\mathrm{pV}$ function parameters. The microstructure of the alloy in the optimized state was observed by transmission electron microscopy (TEM). Magnetic properties before and after TM were measured previously using SQUID magnetometer with a magnetic field strength of $50 \mathrm{kOe}$ [3].

\section{Results and discussion}

The thermomagnetic behaviour of $\mathrm{Nd}_{4.5} \mathrm{Fe}_{77} \mathrm{~B}_{18.5}$ alloy and the corresponding phase transformations were observed by TM. The obtained TM curves are presented in Fig. 1.

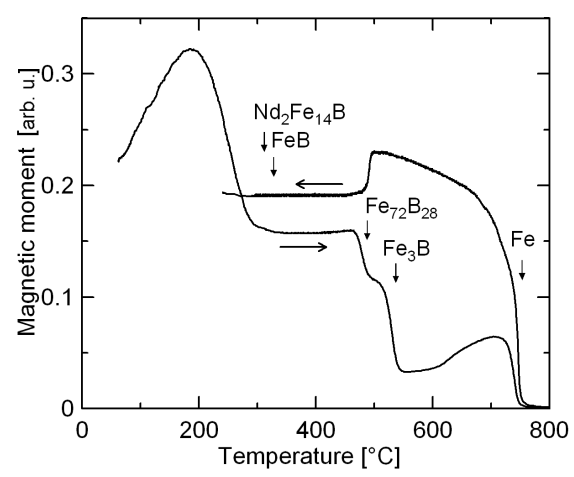

Fig. 1. TM curves of the investigated $\mathrm{Nd}_{4.5} \mathrm{Fe}_{77} \mathrm{~B}_{18.5}$ alloy.

To obtain a better understanding of the influence of phase composition and crystallite size of the identified phases on the magnetic properties before and after TM, size-strain and quantitative phase analyses of the XRD data were performed. Comparisons between observed and calculated intensities before and after TM are presented in Fig. 2. The vertical bars indicate the positions of the reflections and the difference patterns are given below. The amount of the hard and soft magnetic phases and their crystallite sizes, calculated by Full-Prof quantitative phase analysis and size-strain analysis of the XRD data are presented in Table.

In the optimised state of the alloy, $\mathrm{Fe}_{3} \mathrm{~B}, \mathrm{Nd}_{2} \mathrm{Fe}_{14} \mathrm{~B}, \mathrm{Fe}_{77.2} \mathrm{Nd}_{22.8}$ and $\alpha$-Fe phases were identified by XRD analysis. It also suggests that the presence of $\mathrm{Nd}_{2} \mathrm{Fe}_{23} \mathrm{~B}_{3}$ and $\alpha$-Fe could not be neglected [3, 4]. The presence of a $\mathrm{Fe}_{77.2} \mathrm{Nd}_{22.8}$ phase is to be understood more as a representative of $\mathrm{Fe}(\mathrm{Nd}, \mathrm{B})$ components. After the TM according to the XRD results (Fig. 2 and Table), the main decomposition 


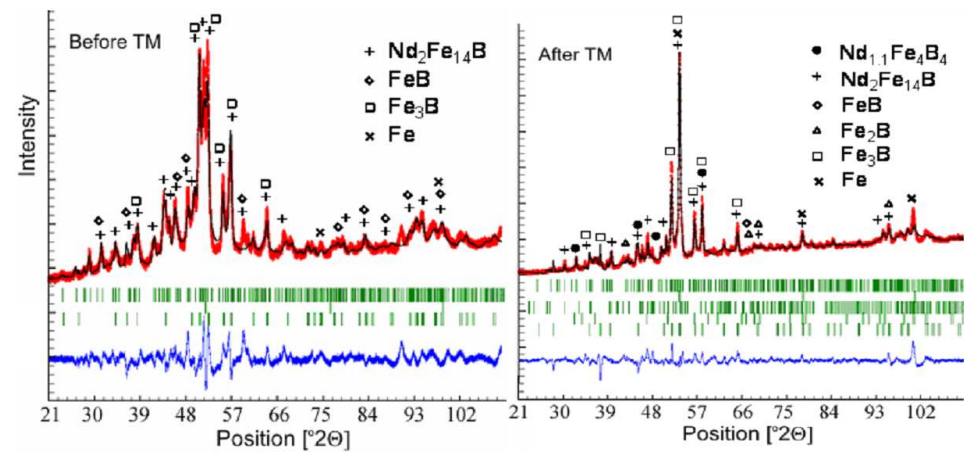

Fig. 2. XRD diffractograms with comparison of observed and calculated intensities.

TABLE

Mean crystallite sizes of phases in the $\mathrm{Nd}_{4.5} \mathrm{Fe}_{77} \mathrm{~B}_{18.5}$ alloy before and after TM.

\begin{tabular}{c|c|c|c|c}
\hline \hline \multirow{2}{*}{ Phase } & \multicolumn{2}{|c|}{ Before TM } & \multicolumn{2}{|c}{ After TM } \\
& Amount [\%] & Crystallite size [nm] & Amount [\%] & Crystallite size [nm] \\
\hline $\mathrm{Nd}_{2} \mathrm{Fe}_{14} \mathrm{~B}$ & 43.6 & 12 & 18.0 & 38 \\
$\alpha-\mathrm{Fe}$ & 16.6 & 5 & 36.8 & 29 \\
$\mathrm{Fe}_{3} \mathrm{~B}$ & 39.8 & 24 & 28.2 & 34 \\
$\mathrm{Nd}_{2} \mathrm{O}_{3}$ & - & - & 8.0 & 8 \\
$\mathrm{Fe}(\mathrm{O}) \mathrm{B}$ & - & - & 9.0 & 11
\end{tabular}

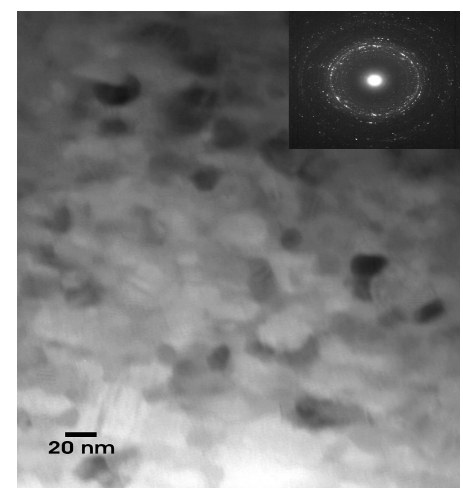

Fig. 3. Bright field TEM micrograph of $\mathrm{Nd}_{4.5} \mathrm{Fe}_{77} \mathrm{~B}_{18.5}$ alloy in the optimised state.

product is $\alpha$-Fe. This phase is accompanied by an $\mathrm{Nd}_{2} \mathrm{Fe}_{14} \mathrm{~B}$ phase, $\mathrm{Fe}_{3} \mathrm{~B}$, and a number of different $\mathrm{Fe}-\mathrm{B}$ phases, as well as a boride phase $\mathrm{Nd}_{1.1} \mathrm{Fe}_{4} \mathrm{~B}_{4}$. The amount of soft magnetic phases had increased (mainly $\alpha$-Fe) and the crystallite size of all identified phases had also increased. The presence of the $\mathrm{Nd}_{2} \mathrm{O}_{3}$ phase was confirmed, too. Practically, this all had a direct influence on the deterioration 
of the magnetic properties. To clarify further the phase constitution, Mössbauer measurements are in progress.

The TEM micrograph (Fig. 3.), showing the average grain size in the optimized magnetic state below $30 \mathrm{~nm}$, confirms the mean crystallite size calculated from the XRD data. Thus, on average, one grain is composed of one crystallite, i.e., all crystalline phases are well crystallized. A microdiffraction analysis gave evidence for the mixing of the nanocrystalline phases. This implies that the alloy has a nanocomposite structure of $\mathrm{Fe}_{3} \mathrm{~B} / \mathrm{Nd}_{2} \mathrm{Fe}_{14} \mathrm{~B}$ and partly $\alpha$-Fe. The phase transformations which occurred during TM are in correspondence with magnetic behaviour as measured by SQUID.

\section{Conclusion}

Both the mean crystallite size and grain size of the investigated alloy in optimal magnetic state determined by XRD and TEM analysis were below $30 \mathrm{~nm}$ indicating that in average one grain is composed of one crystallite i.e. all crystalline phases were well crystallized. Composed of $\mathrm{Nd}_{2} \mathrm{Fe}_{14} \mathrm{~B}, \mathrm{Fe}_{3} \mathrm{~B}$ and $\alpha$-Fe phases, the alloy in the optimized magnetic state has mainly a nanocomposite structure. The value of the remanent ratio $J_{\mathrm{r}} / J_{\mathrm{s}}>0.5$, calculated from the SQUID hysteresis loops [3], suggests that exchange coupling interactions between grains of the soft and hard magnetic phase exist. This assumption is supported by the higher value of the remanence and $(B H)_{\max }$, which are typical of nano-composite structures of $\mathrm{Nd}-\mathrm{Fe}-\mathrm{B}$ alloys.

The increase in temperature during TM resulted in the growth of the crystallites and a decrease in the amount of $\mathrm{Nd}_{2} \mathrm{Fe}_{14} \mathrm{~B}$, due to an increase in the amounts of the $\alpha$-Fe and $\mathrm{Nd}$-oxide fractions, in respect of the optimized magnetic state.

In the light of these facts, it can be concluded that the structural and microstructural changes (phase compositions, crystallite size) have a direct influence on magnetic behaviour and they are the main reason for the deterioration of magnetic properties after TM.

\section{Acknowledgments}

This work was supported by the Serbian Ministry of Science, project OI 142035B and by the Czech Ministry of Education, Youth and Sports, project $1 \mathrm{M} 0512$.

\section{References}

[1] C.J. Yang, E.B. Park, J. Magn. Magn. Mater. 166, 243 (1997).

[2] J. Rodriguez-Carvajal, 1998 FullProf computer program; ftp://charybde.saclay.cea.fr/pub/divers/fullprof.98/windows/winfp98.zip..

[3] V. Ćosović, T. Žák, N. Talijan, A. Grujić, J. Stajić-Trošić, J. Alloys Comp., doi:10.1016/j.jallcom.2007.02.018; in press.

[4] V. Ćosović, A. Grujić, J. Stajić-Trošić, V. Spasojević, N. Talijan, Mater. Sci. Forum 555, 527 (2007). 